\title{
Dioxins Contamination in Sediment and their Effect on Accumulation in the Portuguese Oyster (Crassostrea angulata) and White Shrimp (Litopenaeus Vannamei)
}

Yin-Yu Chen

Department of Aquaculture, National Taiwan Ocean University, Keelung, Taiwan

Yu-Sheng Wu

Department of Aquaculture, National PingTung University of Science and Technology, PingTung, Taiwan

Hsiang-Yin Chen

Department of Aquaculture, National Penghu University of Science and Technology Penghu, Taiwan

Zhen-Hao Liau

Department of Aquaculture, National Taiwan Ocean University, Keelung, Taiwan

Fan-Hua Nan

Department of Aquaculture, National Taiwan Ocean University, Keelung, Taiwan, fhnan@mail.ntou.edu.tw

Follow this and additional works at: https://jmstt.ntou.edu.tw/journal

Part of the Fresh Water Studies Commons, Marine Biology Commons, Ocean Engineering Commons, Oceanography Commons, and the Other Oceanography and Atmospheric Sciences and Meteorology Commons

\section{Recommended Citation}

Chen, Yin-Yu; Wu, Yu-Sheng; Chen, Hsiang-Yin; Liau, Zhen-Hao; and Nan, Fan-Hua (2021) "Dioxins Contamination in Sediment and their Effect on Accumulation in the Portuguese Oyster (Crassostrea angulata) and White Shrimp (Litopenaeus Vannamei)," Journal of Marine Science and Technology. Vol. 29: Iss. 5, Article 9.

DOI: $10.51400 / 2709-6998.2469$

Available at: https://jmstt.ntou.edu.tw/journal/vol29/iss5/9

This Research Article is brought to you for free and open access by Journal of Marine Science and Technology. It has been accepted for inclusion in Journal of Marine Science and Technology by an authorized editor of Journal of Marine Science and Technology. 


\title{
Dioxins Contamination in Sediment and their Effect on Accumulation in the Portuguese Oyster (Crassostrea angulata) and White Shrimp (Litopenaeus Vannamei)
}

\author{
Yin-Yu Chen ${ }^{a}$, Yu-Sheng Wu ${ }^{b}$, Hsiang-Yin Chen ${ }^{c}$, Zhen-Hao Liao ${ }^{a}$, Fan-Hua Nan ${ }^{a, *}$ \\ a Department of Aquaculture, National Taiwan Ocean University, Keelung, Taiwan \\ ${ }^{b}$ Department of Aquaculture, National PingTung University of Science and Technology, PingTung, Taiwan \\ ${ }^{\mathrm{c}}$ Department of Aquaculture, National Penghu University of Science and Technology Penghu, Taiwan
}

\begin{abstract}
This research aims to realize whether the dioxin accumulation in the oyster and white shrimp which were cultured in the dioxin pollutant sediment. This presented evidence indicated that dioxin was detected in all experimental groups with high concentration accumulated in experiment animals. Observation of the concentration, the PCDD/F, 2,3,7,8T4CDD was with high concentration in the sediment and declined with the time elapsed. Detection of the dioxin accumulated in the animal, the accumulative maximum amounts was in the oyster as 3746.16 (pg-TEQ/g d.w.) and in the shrimp as 705.44 (pg-TEQ/g d.w.).

The detected amount of dioxin in the supernatant was quite low, and less to release into the water. The filter habit animal of oyster and demersal habit of white shrimp were both detected the dioxin accumulated in the organs.

As our findings, the dioxin in the sediment is transferred into the oyster and shrimp, the accumulated amount was increased by the bio-magnification with the elapsed time.
\end{abstract}

Keywords: Sediment, Dioxin pollutant, Oyster, White shrimp, Bioaccumulation

\section{Introduction}

$\mathrm{D}$ ioxin has lipophilic properties which is a notorious for persistent and extremely toxic environmental pollutants [10]. It is with the ability of bioaccumulation in the environment food-chain and is able to be absorbed and storage in the animal fatty tissue [7]. Soil is a very important medium for dioxin accumulation and entering the food-chain. Therefore, monitoring the concentration of dioxin in soil can reflect the actually environmental contamination and potential risk for food [21].

Dioxins and dioxin-relative compounds are extremely production of various industrial processes (e.g. waste incineration, iron/steel industries) and expressed in the environmental pollutants, chemically stable and lipid soluble [26]. Current study was investigated that dioxin $(2,3,7,8$-tetrachlorodibenzo [p]dioxin, TCDD) promotes epigenetic transgenerational inheritance of disease [17]. Dioxin is also evidence of carcinogenesis as an environment hazard to alter the host biological response, cell development, differentiation and regulation [25]. Dioxins is primarily stored in the liver followed by the adipose tissue. Once ingestion of dioxins is detectable for a long period and the average half-life of dioxins in the human body is assumed to be seven to nine years [13].

Marine animals contaminated with dioxin are serious concern for human health $[22,23]$, because

Received 23 October 2019; revised 14 May 2020; accepted 30 June 2020.

Available online 18 November 2021.

* Corresponding author. Department of Aquaculture, National Taiwan Ocean University, No.2, Beining Rd., Jhong-jheng District, Keelung City 202. Taiwan.

E-mail address: fhnan@mail.ntou.edu.tw (F.-H. Nan).

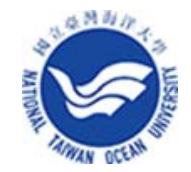


dioxin is able to destroy liver function and fatty acid metabolism, influence enzyme activity, inhibit immune system and cause nerve system dysfunction [18]. Therefore, understanding the potential risk of aquaculture environmental contamination with dioxin is very important. In this research applied different concentration of dioxin (100, 500, 1000 and $1500 \mathrm{ng}-\mathrm{TEQ} / \mathrm{g}$ d.w.) and analyzed the residues in sediment. Moreover, Oyster and white shrimp were used as a model to determine the dioxin uptake rate from sediment. It was hoped that the results can help to contribute a safety standard of dioxin concentration to aquaculture environment. In this analysis of dioxin level, it was using of the Toxic Equivalencies (TEQ, summary weighted measure of their combined toxicity) to realize the level of dioxin in the culture water and experiment animals. TEQs were calculated using as standard the most recent WHO 2005 reevaluation of Toxic Equivalency Factors (TEFs) [8]. dibenzo-p-dioxin), $5 \mu \mathrm{g} / \mathrm{ml}$ Furan mixture $(2,3,7,8$ Tetrachlorinated dibenzofuran, 1,2,3,7,8-Pentachlorinated dibenzofuran, 1,2,3,4,7,8-Hexachlorinated dibenzofuran, 1,2,3,4,6,7,8-Heptachlorinated dibenzofuran, Octachloriated dibenzofuran), $5 \mu \mathrm{g} / \mathrm{ml}$ 1,2,3,6,7,8-Hexachlorinated dibenzo-p-dioxin and $5 \mu \mathrm{g} / \mathrm{ml}$ 1,2,3,7,8,9-Hexachlorinated dibenzo-p-dioxin.

\subsection{Experiment design}

Standard solution was prepared to be the final concentration as A (0; control), B (100), C (500), D (1000), E (1500) ng-TEQ/g and mixed to the sediment. $20 \mathrm{~kg}$ sediment with different concentration of dioxin standard was laid on the bottom of 500 L FRP tank and was cultured with oysters. White shrimps were cultured in $25 \mathrm{~L}$ FRP tank which contained $1 \mathrm{~kg}$ sediment with different concentration of dioxin standard. The experiment procedure was as following and evaluated with every two weeks:

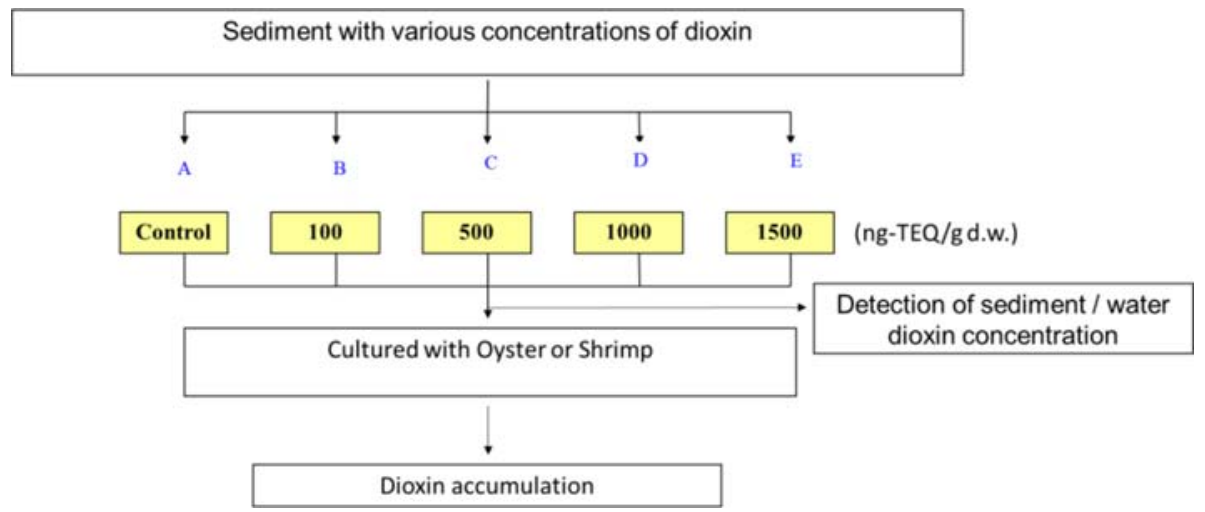

In this research, it was major to realize that after the aquaculture sediment was polluted with various concentrations of dioxin, the impact of the dioxin concentration and the dioxin accumulation in the aquaculture animals. To analog the aquatic animals cultured in the dioxin polluted sediment, the dioxin residue in the shrimp and oyster tissue were measured with elapsed time.

\section{Materials and methods}

\subsection{Standard solution}

Accu Standard contained $5 \mu \mathrm{g} / \mathrm{ml}$ Dioxin mixture (2,3,7,8-Tetrachlorinated dibenzo-p-dioxin, 1,2,3,7,8Pentachlorinated dibenzo-p-dioxin, 1,2,3,4,7,8-Hexachlorinated dibenzo-p-dioxin, 1,2,3,4,6,7,8-Heptachlorinated dibenzo-p-dioxin, Octachlorinated

\subsection{Animals}

Oysters $(6 \mathrm{~kg})$ were purchased from the fish market (Keelung, Taiwan) and white shrimps $(10.0 \pm 2.0 \mathrm{~g}, 80$ individuals in each group) were purchased from Aquatic Animal Center, National Taiwan Ocean University. The residues of dioxin concentration in healthy oysters and white shrimps were confirmed before the experiment inception. Samples were collected and scanning of the dioxin accumulation every two weeks.

\subsection{Dioxin and Furan analysis}

To demonstrate the dioxin concentrations accumulated in the experimental animals, the samples were extracted from the oyster and shrimp tissue. 
The method followed NIEA M801.11 N Dioxin and Furan detection method - HRGC/MS/MS.

Sample extract were dried and filtered over sodium sulfate and glass fiber filters and passed directly to a carbon column. The carbon column was eluted with $50 \mathrm{ml}$ of dichloromethane and then the PCDD/Fs were collected in a $50 \mathrm{ml}$ elution with toluene. The residue from the carbon column was suspended in nhexane. Using Pasteur pipet columns to complete the cleansing: one containing potassium silicate $/ 40 \%$ sulfuric acid on silica gel eluting into a pipet containing $1 \mathrm{~g}$ neutral alumina. PCDDs and PCDFs were recovered from the alumina with $2.5 \mathrm{ml}$ dichloromethane, the extracts were added with $5 \mu \mathrm{L}$ octachloronaphthalene $(\mathrm{OCN})$ served as the recovery standard and an internal standard for quantification in the MS/MS experiments [12].

\subsection{Statistical analysis}

The experimental data in each treatment group were divided by the control group. Tukey's new multiple range test and one-way analysis of variance were used to analyze the statistical significance between the treatment and control groups. A value of $p<0.05$ was considered statistically significant. The results are presented as means \pm standard deviation.

\section{Results}

\subsection{Sediment}

Observation of the initial concentration dioxin in the sediment is shown in Table 1. It was shown that the total PCDD/PCDF in the control sediment, there was no PCDD/F detected. And in other treatment sediment, the detection results were observed as $119.8 \mathrm{pg}-\mathrm{TEQ} / \mathrm{g}, 771.66 \mathrm{pg}-\mathrm{TEQ} / \mathrm{g}, 1356.14 \mathrm{pg}-\mathrm{TEQ} /$ $\mathrm{g}$, and $2078.48 \mathrm{pg}-\mathrm{TEQ} / \mathrm{g}$. With the elapsed time (week) observation, in the 4th week, the concentration of the dioxin was appeared as ND, 96.49, 717.83, 1264.28 and 1981.51 (pg-TEQ/g d.w.) in the control and other treatment groups (Table 2). In the 8th week, the concentration of dioxin was detected as decreased as 90.71, 701.51, 1218.95 and 1866.28 (pgTEQ/g d.w.) (Table 3).

This presented data was illustrated that the concentration of dioxin in the sediment was decreased with the time.

\subsection{Dioxin levels in supernatant water}

Dioxin concentration in cultured water was one of the major parameter that should be concerned. Through the detection time, in the 2nd week, the concentration of dioxin in the water was observed as $\mathrm{ND}, 0.09262,0.6608,1.1898$, and 1.75628 (pg-TEQ/g d.w.) in the control and other groups. In the 4th week, the concentration was shown as ND, 0.0794, $0.7072,1.3086$, and 1.70239 (pg-TEQ/g d.w.). In the 6 th week, the dioxin concentration was that ND, $0.0929,0.6879,1.2619$, and 1.6452 (pg-TEQ/g d.w.). In the 8th week, it was shown as ND, 0.08762, 0.6123, 1.1734, and 1.76288 (pg-TEQ/g d.w.) in the control and other treatment groups.

Analysis of the dioxin compounds in the water with time elapsed. In the 2 nd week, the result was

Table 1. The real dioxin concentration of the sediment in the $0^{\text {th }}$ week. NOTE: ND means No detected and TEQ means Toxicity Equivalent.

\begin{tabular}{|c|c|c|c|c|c|}
\hline Dose (pg-TEQ/g d.w.) & $\mathrm{A}($ Control $)$ & B & $\mathrm{C}$ & $\mathrm{D}$ & $\mathrm{E}$ \\
\hline \multicolumn{6}{|l|}{ Native Compounds } \\
\hline 2,3,7,8-Dioxins & \multicolumn{5}{|c|}{ (pg-TEQ/g d.w.) } \\
\hline 2,3,7,8-T4CDD & ND & 56.86 & 357.43 & 643.28 & 992.48 \\
\hline $1,2,3,7,8-\mathrm{P} 5 \mathrm{CDD}$ & ND & 34.45 & 213.05 & 386.63 & 601.22 \\
\hline $1,2,3,4,7,8-\mathrm{H} 6 \mathrm{CDD}$ & ND & 6.28 & 44.38 & 72.55 & 108.22 \\
\hline $1,2,3,6,7,8-\mathrm{H} 6 \mathrm{CDD}$ & ND & 4.21 & 28.36 & 47.36 & 69.05 \\
\hline 1,2,3,7,8,9-H6CDD & ND & 5.71 & 38.09 & 63.31 & 92.36 \\
\hline $1,2,3,4,6,7,8-H 7 C D D$ & ND & 0.73 & 4.64 & 8.12 & 11.75 \\
\hline OCDD & ND & 0.08 & 0.48 & 0.8 & 1.16 \\
\hline 2,3,7,8-Furans & \multicolumn{5}{|c|}{ (pg-TEQ/g d.w.) } \\
\hline $2,3,7,8-\mathrm{T} 4 \mathrm{CDF}$ & ND & 4.5 & 33.53 & 54.69 & 83.01 \\
\hline $1,2,3,7,8-\mathrm{P} 5 \mathrm{CDF}$ & ND & 2.67 & 22.06 & 30.99 & 48.56 \\
\hline $2,3,4,7,8-\mathrm{P} 5 \mathrm{CDF}$ & ND & ND & ND & ND & ND \\
\hline 1,2,3,4,7,8-H6CDF & ND & 3.64 & 24.18 & 39.66 & 57.88 \\
\hline $1,2,3,6,7,8-\mathrm{H} 6 \mathrm{CDF}$ & ND & ND & ND & ND & ND \\
\hline 1,2,3,7,8,9-H6CDF & ND & ND & ND & ND & ND \\
\hline $2,3,4,6,7,8-\mathrm{H} 6 \mathrm{CDF}$ & ND & ND & ND & ND & ND \\
\hline $1,2,3,4,6,7,8-\mathrm{H} 7 \mathrm{CDF}$ & ND & 0.7 & 5.06 & 8.12 & 11.84 \\
\hline $1,2,3,4,7,8,9-\mathrm{H} 7 \mathrm{CDF}$ & ND & ND & ND & ND & ND \\
\hline OCDF & ND & 0.05 & 0.4 & 0.63 & 0.95 \\
\hline Total PCDD/F (pg-TEQ/g d.w.) & ND & 119.88 & 771.66 & 1356.14 & 2078.48 \\
\hline
\end{tabular}


Table 2. The dioxin concentration of the sediment in the 4th week. NOTE: ND means No detected and TEQ means Toxicity Equivalent.

\begin{tabular}{|c|c|c|c|c|c|}
\hline Dose (pg-TEQ/g d.w.) & $\mathrm{A}($ Control $)$ & B & $\mathrm{C}$ & $\mathrm{D}$ & $\mathrm{E}$ \\
\hline \multicolumn{6}{|l|}{ Native Compounds } \\
\hline 2,3,7,8-Dioxins & \multicolumn{5}{|c|}{ (pg-TEQ/g d.w.) } \\
\hline $2,3,7,8-\mathrm{T} 4 \mathrm{CDD}$ & ND & 42.46 & 317.93 & 593.28 & 952.58 \\
\hline $1,2,3,7,8-\mathrm{P} 5 \mathrm{CDD}$ & ND & 30.49 & 213.05 & 355.71 & 587.29 \\
\hline $1,2,3,4,7,8-\mathrm{H} 6 \mathrm{CDD}$ & ND & 3.28 & 44.18 & 69.43 & 98.21 \\
\hline $1,2,3,6,7,8-\mathrm{H} 6 \mathrm{CDD}$ & ND & 3.21 & 28.28 & 47.36 & 64.04 \\
\hline $1,2,3,7,8,9-\mathrm{H} 6 \mathrm{CDD}$ & ND & 5.71 & 28.09 & 61.11 & 89.45 \\
\hline $1,2,3,4,6,7,8-H 7 C D D$ & ND & 0.73 & 4.34 & 8.99 & 10.75 \\
\hline OCDD & ND & 0.08 & 0.58 & 0.7 & 1.11 \\
\hline 2,3,7,8-Furans & \multicolumn{5}{|c|}{ (pg-TEQ/g d.w.) } \\
\hline $2,3,7,8-\mathrm{T} 4 \mathrm{CDF}$ & ND & 3.5 & 31.23 & 53.63 & 83.01 \\
\hline $1,2,3,7,8-\mathrm{P} 5 \mathrm{CDF}$ & ND & 2.67 & 21.06 & 29.99 & 43.36 \\
\hline $2,3,4,7,8-\mathrm{P} 5 \mathrm{CDF}$ & ND & ND & ND & ND & ND \\
\hline $1,2,3,4,7,8-\mathrm{H} 6 \mathrm{CDF}$ & ND & 3.61 & 24.1 & 34.66 & 37.88 \\
\hline $1,2,3,6,7,8-\mathrm{H} 6 \mathrm{CDF}$ & ND & ND & ND & ND & ND \\
\hline $1,2,3,7,8,9-\mathrm{H} 6 \mathrm{CDF}$ & ND & ND & ND & ND & ND \\
\hline $2,3,4,6,7,8-\mathrm{H} 6 \mathrm{CDF}$ & ND & ND & ND & ND & ND \\
\hline $1,2,3,4,6,7,8-\mathrm{H} 7 \mathrm{CDF}$ & ND & 0.7 & 4.66 & 8.89 & 12.84 \\
\hline $1,2,3,4,7,8,9-\mathrm{H} 7 \mathrm{CDF}$ & ND & ND & ND & ND & ND \\
\hline OCDF & ND & 0.05 & 0.33 & 0.53 & 0.99 \\
\hline Total PCDD/F (pg-TEQ/g d.w.) & ND & 96.49 & 717.83 & 1264.28 & 1981.51 \\
\hline
\end{tabular}

presented that 2,3,7,8-T4CDD, 1,2,3,7,8-P5CDD, 1,2,3,4,7,8-H6CDD, 1,2,3,6,7,8-H6CDD， 1,2,3,7,8,9H6CDD and 1,2,3,4,6,7,8-H7CDD were not observed in the control, however, the $1500 \mathrm{ng}-\mathrm{TEQ} / \mathrm{g}$ d.w. treatment group was presented higher in the $2,3,7$, 8-Dioxins. In the 2,3,7,8-Furans observation, 2,3,7,8T4CDF, 1,2,3,7,8-P5CDF, 2,3,4,7,8-P5CDF, 1,2,3,4,7,8H6CDF, 1,2,3,6,7,8-H6CDF, 1,2,3,7,8,9-H6CDF, 2,3,4,6,7,8-H6CDF, 1,2,3,4,6,7,8-H7CDF, OCDF and
$1,2,3,4,7,8,9-\mathrm{H} 7 \mathrm{CDF}$ were not observed in the control (Table 4).

In the 4th week, 2,3,7,8-T4CDD, 1,2,3,7,8-P5CDD, 1,2,3,4,7,8-H6CDD, 1,2,3,6,7,8-H6CDD， 1,2,3,7,8,9H6CDD and, 1,2,3,4,6,7,8-H7CDD were observed in the treatment groups. However, in the 2,3,7,8-Furan compound, there were 2,3,7,8-T4CDF, 1,2,3,7,8P5CDF, 1,2,3,4,7,8-H6CDF, 1,2,3,4,6,7,8-H7CDF and OCDF detected in the treatment (Table 5). In the 6th

Table 3. The dioxin concentration of the sediment in the 8th week. NOTE: ND means No detected and TEQ means Toxicity Equivalent.

\begin{tabular}{|c|c|c|c|c|c|}
\hline Dose (pg-TEQ/g d.w.) & $\mathrm{A}($ Control $)$ & B & $\mathrm{C}$ & $\mathrm{D}$ & $E$ \\
\hline \multicolumn{6}{|l|}{ Native Compounds } \\
\hline 2,3,7,8-Dioxins & \multicolumn{5}{|c|}{ (pg-TEQ/g d.w.) } \\
\hline $2,3,7,8-\mathrm{T} 4 \mathrm{CDD}$ & ND & 39.36 & 301.93 & 577.27 & 933.53 \\
\hline $1,2,3,7,8-\mathrm{P} 5 \mathrm{CDD}$ & ND & 28.89 & 213.05 & 335.77 & 517.29 \\
\hline $1,2,3,4,7,8-\mathrm{H} 6 \mathrm{CDD}$ & ND & 3.01 & 44.18 & 67.43 & 95.21 \\
\hline $1,2,3,6,7,8-\mathrm{H} 6 \mathrm{CDD}$ & ND & 3.11 & 28.28 & 47.22 & 61.04 \\
\hline $1,2,3,7,8,9-\mathrm{H} 6 \mathrm{CDD}$ & ND & 5.23 & 28.09 & 63.13 & 79.41 \\
\hline $1,2,3,4,6,7,8-\mathrm{H} 7 \mathrm{CDD}$ & ND & 0.65 & 4.34 & 8.54 & 10.65 \\
\hline OCDD & ND & 0.08 & 0.58 & 0.7 & 1.17 \\
\hline 2,3,7,8-Furans & \multicolumn{5}{|c|}{ (pg-TEQ/g d.w.) } \\
\hline $2,3,7,8-\mathrm{T} 4 \mathrm{CDF}$ & ND & 3.3 & 31.23 & 51.13 & 82.77 \\
\hline $1,2,3,7,8-\mathrm{P} 5 \mathrm{CDF}$ & ND & 2.66 & 21.06 & 24.19 & 41.31 \\
\hline $2,3,4,7,8-\mathrm{P} 5 \mathrm{CDF}$ & ND & ND & ND & ND & ND \\
\hline $1,2,3,4,7,8-\mathrm{H} 6 \mathrm{CDF}$ & ND & 3.65 & 24.1 & 34.64 & 31.89 \\
\hline $1,2,3,6,7,8-\mathrm{H} 6 \mathrm{CDF}$ & ND & ND & ND & ND & ND \\
\hline $1,2,3,7,8,9-\mathrm{H} 6 \mathrm{CDF}$ & ND & ND & ND & ND & ND \\
\hline $2,3,4,6,7,8-\mathrm{H} 6 \mathrm{CDF}$ & ND & ND & ND & ND & ND \\
\hline $1,2,3,4,6,7,8-\mathrm{H} 7 \mathrm{CDF}$ & ND & 0.7 & 4.36 & 8.44 & 11.14 \\
\hline $1,2,3,4,7,8,9-\mathrm{H} 7 \mathrm{CDF}$ & ND & ND & ND & ND & ND \\
\hline OCDF & ND & 0.07 & 0.31 & 0.49 & 0.87 \\
\hline Total PCDD/F (pg-TEQ/g d.w.) & ND & 90.71 & 701.51 & 1218.95 & 1866.28 \\
\hline
\end{tabular}


Table 4. The dioxin concentration of the culture water in the 2nd week. NOTE: ND means No detected and TEQ means Toxicity Equivalent.

\begin{tabular}{|c|c|c|c|c|c|}
\hline Dose (pg-TEQ/g d.w.) & $\mathrm{A}($ Control $)$ & $\mathrm{B}$ & $\mathrm{C}$ & $\mathrm{D}$ & $\mathrm{E}$ \\
\hline \multicolumn{6}{|l|}{ Native Compounds } \\
\hline 2,3,7,8-Dioxins & \multicolumn{5}{|c|}{ (pg-TEQ/g d.w.) } \\
\hline $2,3,7,8-\mathrm{T} 4 \mathrm{CDD}$ & ND & 0.0316 & 0.2993 & 0.5707 & 0.8953 \\
\hline $1,2,3,7,8-\mathrm{P} 5 \mathrm{CDD}$ & ND & 0.0298 & 0.1905 & 0.3577 & 0.5021 \\
\hline $1,2,3,4,7,8-\mathrm{H} 6 \mathrm{CDD}$ & ND & 0.0013 & 0.0418 & 0.0783 & 0.0931 \\
\hline $1,2,3,6,7,8-\mathrm{H} 6 \mathrm{CDD}$ & ND & 0.0011 & 0.0228 & 0.0412 & 0.0604 \\
\hline $1,2,3,7,8,9-\mathrm{H} 6 \mathrm{CDD}$ & ND & 0.0066 & 0.0209 & 0.0313 & 0.0791 \\
\hline $1,2,3,4,6,7,8-H 7 C D D$ & ND & 0.0007 & 0.0034 & 0.0054 & 0.0115 \\
\hline OCDD & ND & 0.00009 & 0.0003 & 0.0007 & 0.0017 \\
\hline 2,3,7,8-Furans & \multicolumn{5}{|c|}{ (pg-TEQ/g d.w.) } \\
\hline $2,3,7,8-\mathrm{T} 4 \mathrm{CDF}$ & ND & 0.003 & 0.0323 & 0.0515 & 0.0277 \\
\hline $1,2,3,7,8-\mathrm{P} 5 \mathrm{CDF}$ & ND & 0.0066 & 0.0206 & 0.0119 & 0.0431 \\
\hline $2,3,4,7,8-\mathrm{P} 5 \mathrm{CDF}$ & ND & ND & ND & ND & ND \\
\hline $1,2,3,4,7,8-\mathrm{H} 6 \mathrm{CDF}$ & ND & 0.0111 & 0.0251 & 0.0364 & 0.0309 \\
\hline $1,2,3,6,7,8-\mathrm{H} 6 \mathrm{CDF}$ & ND & ND & ND & ND & ND \\
\hline $1,2,3,7,8,9-\mathrm{H} 6 \mathrm{CDF}$ & ND & ND & ND & ND & ND \\
\hline $2,3,4,6,7,8-\mathrm{H} 6 \mathrm{CDF}$ & ND & ND & ND & ND & ND \\
\hline $1,2,3,4,6,7,8-\mathrm{H} 7 \mathrm{CDF}$ & ND & 0.0007 & 0.0035 & 0.0044 & 0.0113 \\
\hline $1,2,3,4,7,8,9-\mathrm{H} 7 \mathrm{CDF}$ & ND & ND & ND & ND & ND \\
\hline OCDF & ND & 0.00003 & 0.0003 & 0.0003 & 0.00008 \\
\hline Total PCDD/F (pg-TEQ/g d.w.) & ND & 0.09262 & 0.6608 & 1.1898 & 1.75628 \\
\hline
\end{tabular}

week, the 2,3,7,8-Dioxin compounds were detected in the treatment groups. In the 2,3,7,8-Furan compound, there were $2,3,7,8-\mathrm{T} 4 \mathrm{CDF}, 1,2,3,7,8-\mathrm{P} 5 \mathrm{CDF}$, 1,2,3,4,7,8-H6CDF, 1,2,3,4,6,7,8-H7CDF and OCDF detected in the treatment (Table 6). In the 8th week, the concentration of dioxin compounds was lower than in the 6th week (Table 7).

It was presented that the detected amount of dioxin in the supernatant was lower than in the sediment and dioxin accumulated in the animals.

\subsection{Accumulation in oyster}

The concentration of PCDD/PCDF congener in oysters which were cultured with different standard sediment were under monitored. It was obviously that the oysters which were cultured with high concentration PCDD/PCDF sediment exhibited higher bioaccumulation and showed dose dependent. 2,3,7,8-T4CDD was detected in all experimental groups and showed higher concentration

Table 5. The dioxin concentration of the culture water in the 4th week. NOTE: ND means No detected and TEQ means Toxicity Equivalent.

\begin{tabular}{|c|c|c|c|c|c|}
\hline Dose (pg-TEQ/g d.w.) & $\mathrm{A}($ Control $)$ & B & $\mathrm{C}$ & $\mathrm{D}$ & $\mathrm{E}$ \\
\hline \multicolumn{6}{|l|}{ Native Compounds } \\
\hline 2,3,7,8-Dioxins & \multicolumn{5}{|c|}{ (pg-TEQ/g d.w.) } \\
\hline $2,3,7,8-\mathrm{T} 4 \mathrm{CDD}$ & ND & 0.0213 & 0.3593 & 0.7101 & 0.7743 \\
\hline 1,2,3,7,8-P5CDD & ND & 0.0238 & 0.1741 & 0.3337 & 0.5511 \\
\hline $1,2,3,4,7,8-\mathrm{H} 6 \mathrm{CDD}$ & ND & 0.0023 & 0.0333 & 0.1053 & 0.0891 \\
\hline $1,2,3,6,7,8-\mathrm{H} 6 \mathrm{CDD}$ & ND & 0.0012 & 0.0234 & 0.0442 & 0.0704 \\
\hline $1,2,3,7,8,9-\mathrm{H} 6 \mathrm{CDD}$ & ND & 0.0056 & 0.0209 & 0.0333 & 0.0788 \\
\hline $1,2,3,4,6,7,8-\mathrm{H} 7 \mathrm{CDD}$ & ND & 0.0005 & 0.0074 & 0.0084 & 0.0133 \\
\hline OCDD & ND & 0.0001 & 0.0023 & 0.0009 & 0.0022 \\
\hline 2,3,7,8-Furans & \multicolumn{5}{|c|}{ (pg-TEQ/g d.w.) } \\
\hline $2,3,7,8-\mathrm{T} 4 \mathrm{CDF}$ & ND & 0.004 & 0.0423 & 0.0315 & 0.0347 \\
\hline $1,2,3,7,8-\mathrm{P} 5 \mathrm{CDF}$ & ND & 0.0076 & 0.0206 & 0.0101 & 0.0431 \\
\hline 2,3,4,7,8-P5CDF & ND & ND & ND & ND & ND \\
\hline $1,2,3,4,7,8-\mathrm{H} 6 \mathrm{CDF}$ & ND & 0.0112 & 0.0201 & 0.0304 & 0.03 \\
\hline $1,2,3,6,7,8-\mathrm{H} 6 \mathrm{CDF}$ & ND & ND & ND & ND & ND \\
\hline 1,2,3,7,8,9-H6CDF & ND & ND & ND & ND & ND \\
\hline $2,3,4,6,7,8-\mathrm{H} 6 \mathrm{CDF}$ & ND & ND & ND & ND & ND \\
\hline $1,2,3,4,6,7,8-\mathrm{H} 7 \mathrm{CDF}$ & ND & 0.0017 & 0.0033 & 0.0004 & 0.0153 \\
\hline $1,2,3,4,7,8,9-\mathrm{H} 7 \mathrm{CDF}$ & ND & ND & ND & ND & ND \\
\hline OCDF & ND & 0.0001 & 0.0002 & 0.0003 & 0.00009 \\
\hline Total PCDD/F (pg-TEQ/g d.w.) & ND & 0.0794 & 0.7072 & 1.3086 & 1.70239 \\
\hline
\end{tabular}


Table 6. The dioxin concentration of the culture water in the 6th week. NOTE: ND means No detected and TEQ means Toxicity Equivalent.

\begin{tabular}{lllll}
\hline Dose (pg-TEQ/g d.w.) & A(Control) & B & C & D \\
\hline Native Compounds & & & & E \\
2,3,7,8-Dioxins & (pg-TEQ/g d.w.) & & & 0.6691 \\
$2,3,7,8-T 4 C D D$ & ND & 0.0205 & 0.2993 & 0.3117 \\
$1,2,3,7,8-P 5 C D D$ & ND & 0.0338 & 0.1941 & 0.1123 \\
$1,2,3,4,7,8-H 6 C D D$ & ND & 0.0033 & 0.0393 & 0.0499 \\
$1,2,3,6,7,8-H 6 C D D$ & ND & 0.0012 & 0.0301 & 0.0321 \\
$1,2,3,7,8,9-H 6 C D D$ & ND & 0.0064 & 0.0203 & 0.0089 \\
$1,2,3,4,6,7,8-H 7 C D D$ & ND & 0.0009 & 0.0063 & 0.0008 \\
OCDD & ND & 0.0002 & 0.0033 & 0.0711 \\
$2,3,7,8-F u r a n s$ & (pg-TEQ/g d.w.) & & & 0.0688 \\
$2,3,7,8-T 4 C D F$ & ND & 0.0044 & 0.0501 & 0.0013 \\
$1,2,3,7,8-P 5 C D F$ & ND & 0.0097 & 0.0196 & 0.0322 \\
$2,3,4,7,8-P 5 C D F$ & ND & ND & ND & ND \\
$1,2,3,4,7,8-H 6 C D F$ & ND & 0.0102 & 0.0211 & 0.0319 \\
$1,2,3,6,7,8-H 6 C D F$ & ND & ND & ND & ND \\
$1,2,3,7,8,9-H 6 C D F$ & ND & ND & ND & ND \\
$2,3,4,6,7,8-H 6 C D F$ & ND & ND & ND & ND \\
$1,2,3,4,6,7,8-H 7 C D F$ & ND & 0.0022 & 0.0032 & 0.0299 \\
$1,2,3,4,7,8,9-H 7 C D F$ & ND & ND & ND & ND \\
OCDF & ND & 0.0001 & 0.0012 & ND \\
Total PCDD/F (pg-TEQ/g d.w.) & ND & 0.0929 & 0.6879 & ND \\
\hline
\end{tabular}

then other PCDD/F congener. Data of 2,3,7,8T4CDD was showed in Fig. 1B. It was believed that the accumulation of PCDD/F in human and animal were through food consumption. In the 2nd week, the 2,3,7,8-Dioxin compounds were observed in the treatment groups, especially, 1,2,3,7,8-P5CDD, $1,2,3,4,6,7,8-$ H7CDD and OCDD were detected in the control oyster group. In the 2,3,7,8-Furans compounds, 2,3,7,8-T4CDF and 1,2,3,7,8-P5CDF were observed in all of the groups. 2,3,4,7,8-P5CDF, 1,2,3,6,7,8-H6CDF and 2,3,4,6,7,8-H6CDF were only detected as $0.85,0.15$ and $0.11 \mathrm{pg}-\mathrm{TEQ} / \mathrm{g}$ in the treatment of $1000 \mathrm{ng}-\mathrm{TEQ} / \mathrm{g}$ group (Table 8 ). In the 4th week, 1,2,3,7,8-P5CDD, 1,2,3,4,6,7,8-H7CDD and OCDD were observed in all of the groups. In the 2,3,7,8-Furan compounds, 2,3,7,8-T4CDF and $1,2,3,7,8-P 5 C D F$ were the main accumulated in the oyster, moreover, $2,3,4,7,8-\mathrm{P} 5 \mathrm{CDF}$ was observed in

Table 7. The dioxin concentration of the culture water in the 8th week. NOTE: ND means No detected and TEQ means Toxicity Equivalent.

\begin{tabular}{lllll}
\hline Dose (pg-TEQ/g d.w.) & A(Control) & B & C & D \\
\hline Native Compounds & & & & E \\
$2,3,7,8-$-Dioxins & (pg-TEQ/g d.w.) & & & 0.5378 \\
$2,3,7,8-T 4 C D D$ & ND & 0.0248 & 0.2483 & 0.3587 \\
$1,2,3,7,8-$-P5CDD & ND & 0.0283 & 0.1805 & 0.0883 \\
$1,2,3,4,7,8-H 6 C D D$ & ND & 0.0023 & 0.0478 & 0.0418 \\
$1,2,3,6,7,8-H 6 C D D$ & ND & 0.0009 & 0.0228 & 0.0313 \\
$1,2,3,7,8,9-H 6 C D D$ & ND & 0.0076 & 0.0208 & 0.0074 \\
$1,2,3,4,6,7,8-H 7 C D D$ & ND & 0.0008 & 0.0037 & 0.0008 \\
OCDD & ND & 0.0001 & 0.0008 & 0.0604 \\
$2,3,7,8-$ Furans & (pg-TEQ/g d.w.) & & & 0.0798 \\
$2,3,7,8-T 4 C D F$ & ND & 0.0029 & 0.0313 & 0.0017 \\
$1,2,3,7,8-P 5 C D F$ & ND & 0.0069 & 0.0256 & 0.0115 \\
$2,3,4,7,8-P 5 C D F$ & ND & ND & ND & ND \\
$1,2,3,4,7,8-H 6 C D F$ & ND & 0.0121 & 0.0251 & 0.0374 \\
$1,2,3,6,7,8-H 6 C D F$ & ND & ND & ND & ND \\
$1,2,3,7,8,9-H 6 C D F$ & ND & ND & ND & ND \\
$2,3,4,6,7,8-H 6 C D F$ & ND & ND & ND & ND \\
$1,2,3,4,6,7,8-H 7 C D F$ & ND & 0.0009 & 0.0055 & 0.0311 \\
$1,2,3,4,7,8,9-H 7 C D F$ & ND & ND & ND & ND \\
OCDF & ND & 0.00002 & 0.0001 & ND \\
Total PCDD/F (pg-TEQ/g d.w.) & ND & 0.08762 & 0.6123 & 0.0034 \\
\end{tabular}


A

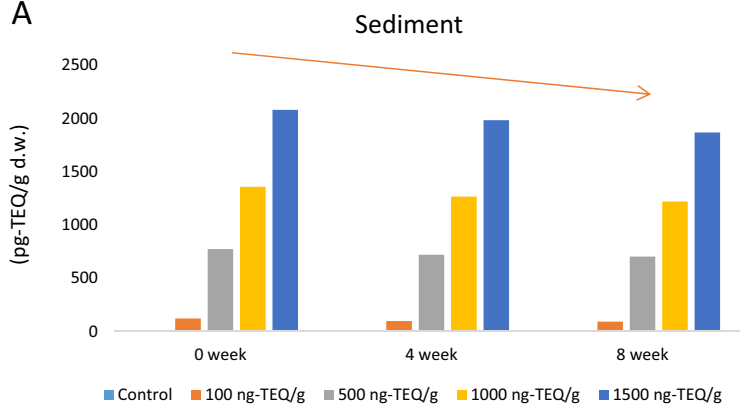

C

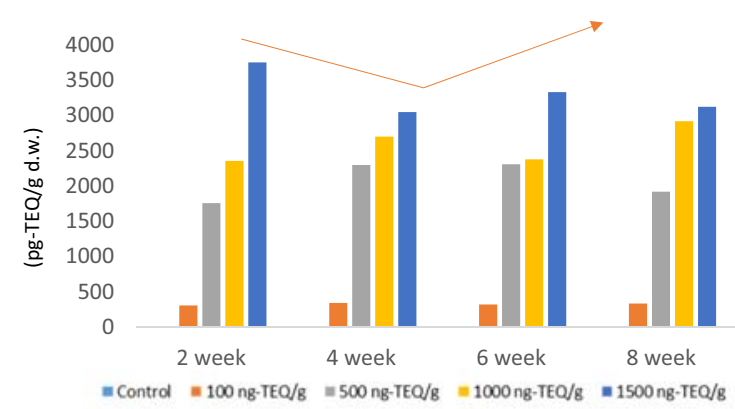

B

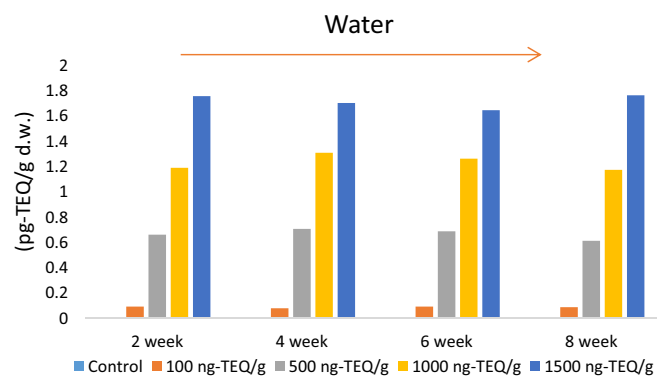

D

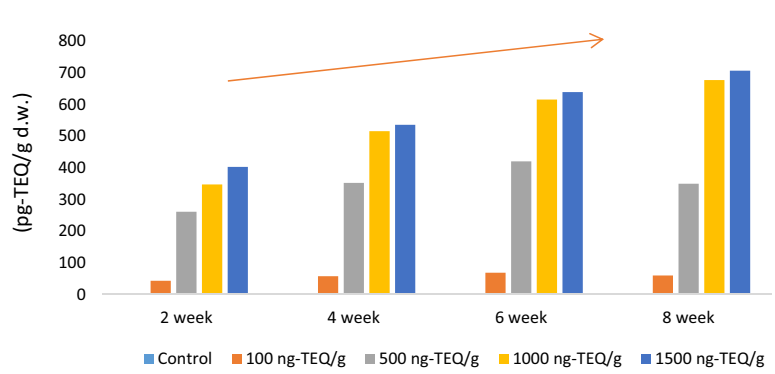

Fig. 1. Trend of the dioxin concentration in the different mediums as sediment, culture water, oyster and shrimp. (A) The dioxin in the sediment is changed in the $0^{\text {th }}, 4^{\text {th }}$, and $8^{\text {th }}$ week observation. (B) The dioxin in the culture water is changed in the $2^{\text {nd }}, 4^{\text {th }}, 6^{\text {th }}$ and $8^{\text {th }}$ week observation. (C) The dioxin accumulated in the oyster is changed in the $2^{\text {nd }}, 4^{\text {th }}, 6^{\text {th }}$ and $8^{\text {th }}$ week observation. (D) The dioxin accumulated in the shrimp is changed in the $2^{\text {nd }}, 4^{\text {th }}, 6^{\text {th }}$ and $8^{\text {th }}$ week observation.

Table 8. The accumulate dioxin concentration of the culture oyster in the 2nd week. NOTE: ND means No detected and TEQ means Toxicity Equivalent.

\begin{tabular}{|c|c|c|c|c|c|}
\hline Dose (pg-TEQ/g d.w.) & $\mathrm{A}($ Control $)$ & B & $\mathrm{C}$ & $\mathrm{D}$ & $\mathrm{E}$ \\
\hline \multicolumn{6}{|l|}{ Native Compounds } \\
\hline 2,3,7,8-Dioxins & \multicolumn{5}{|c|}{ (pg-TEQ/g d.w.) } \\
\hline 2,3,7,8-T4CDD & ND & 193.38 & 1127.90 & 1531.63 & 2473.11 \\
\hline 1,2,3,7,8-P5CDD & 0.33 & 76.33 & 433.73 & 550.26 & 862.01 \\
\hline $1,2,3,4,7,8-\mathrm{H} 6 \mathrm{CDD}$ & ND & 5.12 & 27.86 & 35.55 & 48.70 \\
\hline $1,2,3,6,7,8-\mathrm{H} 6 \mathrm{CDD}$ & ND & 4.16 & 22.33 & 29.09 & 41.19 \\
\hline 1,2,3,7,8,9-H6CDD & ND & 4.49 & 24.27 & 31.28 & 42.86 \\
\hline $1,2,3,4,6,7,8-\mathrm{H} 7 \mathrm{CDD}$ & 0.02 & 0.17 & 0.73 & 1.25 & 1.54 \\
\hline OCDD & 0.01 & 0.02 & 0.05 & 0.08 & 0.10 \\
\hline 2,3,7,8-Furans & \multicolumn{5}{|c|}{ (pg-TEQ/g d.w.) } \\
\hline $2,3,7,8-\mathrm{T} 4 \mathrm{CDF}$ & 0.17 & 17.65 & 91.46 & 134.65 & 228.75 \\
\hline $1,2,3,7,8-\mathrm{P} 5 \mathrm{CDF}$ & 0.04 & 3.97 & 24.42 & 34.10 & 43.95 \\
\hline 2,3,4,7,8-P5CDF & ND & ND & ND & 0.85 & ND \\
\hline $1,2,3,4,7,8-\mathrm{H} 6 \mathrm{CDF}$ & ND & 0.22 & 1.03 & 2.89 & 2.70 \\
\hline $1,2,3,6,7,8-\mathrm{H} 6 \mathrm{CDF}$ & ND & ND & ND & 0.12 & ND \\
\hline 1,2,3,7,8,9-H6CDF & ND & ND & ND & ND & ND \\
\hline $2,3,4,6,7,8-\mathrm{H} 6 \mathrm{CDF}$ & ND & ND & ND & 0.11 & ND \\
\hline $1,2,3,4,6,7,8-\mathrm{H} 7 \mathrm{CDF}$ & ND & 0.10 & 0.49 & 1.06 & 1.17 \\
\hline $1,2,3,4,7,8,9-\mathrm{H} 7 \mathrm{CDF}$ & ND & ND & ND & ND & ND \\
\hline OCDF & ND & 0.001 & 0.04 & 0.07 & 0.08 \\
\hline Total PCDD/F (pg-TEQ/g d.w.) & 0.57 & 305.61 & 1754.31 & 2352.99 & 3746.16 \\
\hline
\end{tabular}


Table 9. The accumulate dioxin concentration of the culture oyster in the 4th week. NOTE: ND means No detected and TEQ means Toxicity Equivalent.

\begin{tabular}{|c|c|c|c|c|c|}
\hline Dose (pg-TEQ/g d.w.) & $\mathrm{A}($ Control $)$ & B & $\mathrm{C}$ & $\mathrm{D}$ & $\mathrm{E}$ \\
\hline \multicolumn{6}{|l|}{ Native Compounds } \\
\hline 2,3,7,8-Dioxins & \multicolumn{5}{|c|}{ (pg-TEQ/g d.w.) } \\
\hline $2,3,7,8-\mathrm{T} 4 \mathrm{CDD}$ & ND & 218.52 & 1500.11 & 1700.11 & 1910.63 \\
\hline 1,2,3,7,8-P5CDD & 0.18 & 86.25 & 576.86 & 610.78 & 752.55 \\
\hline $1,2,3,4,7,8-H 6 C D D$ & ND & 5.78 & 37.05 & 39.46 & 48.62 \\
\hline $1,2,3,6,7,8-H 6 C D D$ & ND & 4.70 & 29.70 & 32.29 & 39.78 \\
\hline $1,2,3,7,8,9-\mathrm{H} 6 \mathrm{CDD}$ & ND & 3.95 & 32.28 & 34.72 & 42.77 \\
\hline $1,2,3,4,6,7,8-\mathrm{H} 7 \mathrm{CDD}$ & 0.01 & 0.22 & 0.96 & 1.39 & 1.72 \\
\hline OCDD & 0.01 & 0.01 & 0.06 & 0.09 & 0.12 \\
\hline 2,3,7,8-Furans & \multicolumn{5}{|c|}{ (pg-TEQ/g d.w.) } \\
\hline $2,3,7,8-\mathrm{T} 4 \mathrm{CDF}$ & 0.20 & 17.65 & 91.46 & 228.75 & 203.59 \\
\hline $1,2,3,7,8-\mathrm{P} 5 \mathrm{CDF}$ & 0.13 & 3.97 & 24.42 & 43.95 & 39.12 \\
\hline 2,3,4,7,8-P5CDF & 0.03 & ND & ND & ND & 0.85 \\
\hline $1,2,3,4,7,8-\mathrm{H} 6 \mathrm{CDF}$ & ND & 0.22 & 1.03 & 2.70 & 2.89 \\
\hline $1,2,3,6,7,8-\mathrm{H} 6 \mathrm{CDF}$ & ND & ND & ND & ND & 0.12 \\
\hline $1,2,3,7,8,9-\mathrm{H} 6 \mathrm{CDF}$ & ND & ND & ND & ND & ND \\
\hline $2,3,4,6,7,8-\mathrm{H} 6 \mathrm{CDF}$ & ND & ND & ND & ND & 0.11 \\
\hline $1,2,3,4,6,7,8-\mathrm{H} 7 \mathrm{CDF}$ & ND & 0.10 & 0.49 & 1.17 & 1.06 \\
\hline $1,2,3,4,7,8,9-\mathrm{H} 7 \mathrm{CDF}$ & ND & ND & ND & ND & ND \\
\hline OCDF & ND & 0.002 & 0.04 & 0.08 & 0.07 \\
\hline Total PCDD/F (pg-TEQ/g d.w.) & 0.55 & 341.40 & 2294.48 & 2695.49 & 3043.99 \\
\hline
\end{tabular}

the control and treatment 1500 (ng-TEQ/g d.w.) (Table 9).

In the 6th week, 1,2,3,7,8-P5CDD, 1,2,3,4,6,7,8H7CDD and OCDD were detected in the all of the groups, especially, 2,3,7,8-T4CDD was higher in the accumulated in the oyster. In the 2,3,7,8-Furans compounds, the 2,3,7,8-T4CDF and 1,2,3,7,8-P5CDF were detected increased in the oyster, moreover,
2,3,4,7,8-P5CDF was decreased as ND compared to the 4 th week observation (Table 10). In the 8 th week, the detection of the dioxin was similar to the 6th week (Table 11).

In generally, 1,2,3,7,8-P5CDD, 1,2,3,4,6,7,8H7CDD, OCDD, 2,3,7,8-T4CDF and 1,2,3,7,8-P5CDF were accumulated in the oyster even in the control oyster. Especially, 2,3,4,7,8-P5CDF was observed in

Table 10. The accumulate dioxin concentration of the culture oyster in the 6th week. NOTE: ND means No detected and TEQ means Toxicity Equivalent.

\begin{tabular}{|c|c|c|c|c|c|}
\hline Dose (pg-TEQ/g d.w.) & $\mathrm{A}($ Control $)$ & B & $\mathrm{C}$ & $\mathrm{D}$ & $\mathrm{E}$ \\
\hline \multicolumn{6}{|l|}{ Native Compounds } \\
\hline 2,3,7,8-Dioxins & \multicolumn{5}{|c|}{ (pg-TEQ/g d.w.) } \\
\hline $2,3,7,8-\mathrm{T} 4 \mathrm{CDD}$ & ND & 202.42 & 1495.23 & 1535.51 & 2037.81 \\
\hline 1,2,3,7,8-P5CDD & 0.11 & 79.89 & 574.98 & 551.65 & 875.49 \\
\hline $1,2,3,4,7,8-\mathrm{H} 6 \mathrm{CDD}$ & ND & 5.36 & 36.93 & 35.64 & 49.46 \\
\hline $1,2,3,6,7,8-\mathrm{H} 6 \mathrm{CDD}$ & ND & 4.36 & 29.60 & 29.16 & 41.84 \\
\hline $1,2,3,7,8,9-\mathrm{H} 6 \mathrm{CDD}$ & ND & 4.70 & 32.18 & 31.36 & 43.53 \\
\hline $1,2,3,4,6,7,8-H 7 C D D$ & 0.01 & 0.17 & 0.96 & 1.26 & 1.57 \\
\hline OCDD & 0.01 & 0.02 & 0.06 & 0.09 & 0.10 \\
\hline 2,3,7,8-Furans & \multicolumn{5}{|c|}{ (pg-TEQ/g d.w.) } \\
\hline $2,3,7,8-\mathrm{T} 4 \mathrm{CDF}$ & 0.27 & 18.48 & 104.88 & 148.08 & 228.85 \\
\hline $1,2,3,7,8-\mathrm{P} 5 \mathrm{CDF}$ & 0.03 & 4.16 & 28.00 & 37.51 & 43.97 \\
\hline $2,3,4,7,8-\mathrm{P} 5 \mathrm{CDF}$ & ND & ND & ND & ND & ND \\
\hline $1,2,3,4,7,8-\mathrm{H} 6 \mathrm{CDF}$ & ND & 0.23 & 1.19 & 3.18 & 2.70 \\
\hline $1,2,3,6,7,8-\mathrm{H} 6 \mathrm{CDF}$ & ND & ND & ND & ND & 0.12 \\
\hline $1,2,3,7,8,9-\mathrm{H} 6 \mathrm{CDF}$ & ND & ND & ND & ND & ND \\
\hline $2,3,4,6,7,8-\mathrm{H} 6 \mathrm{CDF}$ & ND & ND & ND & ND & ND \\
\hline $1,2,3,4,6,7,8-\mathrm{H} 7 \mathrm{CDF}$ & ND & 0.10 & 0.57 & 1.17 & 1.17 \\
\hline $1,2,3,4,7,8,9-\mathrm{H} 7 \mathrm{CDF}$ & ND & ND & ND & ND & ND \\
\hline OCDF & ND & 0.001 & 0.04 & 0.08 & 0.08 \\
\hline Total PCDD/F (pg-TEQ/g d.w.) & 0.43 & 319.89 & 2304.62 & 2374.67 & 3326.69 \\
\hline
\end{tabular}


Table 11. The accumulate dioxin concentration of the culture oyster in the 8th week. NOTE: ND means No detected and TEQ means Toxicity Equivalent.

\begin{tabular}{|c|c|c|c|c|c|}
\hline Dose (pg-TEQ/g d.w.) & $\mathrm{A}($ Control $)$ & B & $\mathrm{C}$ & $\mathrm{D}$ & $\mathrm{E}$ \\
\hline \multicolumn{6}{|l|}{ Native Compounds } \\
\hline 2,3,7,8-Dioxins & \multicolumn{5}{|c|}{ (pg-TEQ/g d.w.) } \\
\hline $2,3,7,8-\mathrm{T} 4 \mathrm{CDD}$ & ND & 211.34 & 1232.61 & 1923.51 & 2030.46 \\
\hline $1,2,3,7,8-\mathrm{P} 5 \mathrm{CDD}$ & 0.13 & 83.41 & 473.99 & 670.45 & 729.47 \\
\hline $1,2,3,4,7,8-\mathrm{H} 6 \mathrm{CDD}$ & ND & 5.59 & 30.44 & 37.88 & 47.13 \\
\hline $1,2,3,6,7,8-\mathrm{H} 6 \mathrm{CDD}$ & ND & 4.55 & 24.40 & 32.04 & 38.56 \\
\hline $1,2,3,7,8,9-\mathrm{H} 6 \mathrm{CDD}$ & ND & 4.91 & 26.53 & 33.34 & 41.46 \\
\hline $1,2,3,4,6,7,8-H 7 C D D$ & 0.01 & 0.18 & 0.79 & 1.20 & 1.66 \\
\hline OCDD & 0.01 & 0.02 & 0.05 & 0.08 & 0.11 \\
\hline 2,3,7,8-Furans & \multicolumn{5}{|c|}{ (pg-TEQ/g d.w.) } \\
\hline $2,3,7,8-\mathrm{T} 4 \mathrm{CDF}$ & 0.25 & 19.29 & 99.95 & 177.91 & 178.50 \\
\hline $1,2,3,7,8-\mathrm{P} 5 \mathrm{CDF}$ & 0.02 & 4.34 & 26.69 & 34.18 & 45.21 \\
\hline $2,3,4,7,8-\mathrm{P} 5 \mathrm{CDF}$ & ND & ND & ND & ND & ND \\
\hline $1,2,3,4,7,8-\mathrm{H} 6 \mathrm{CDF}$ & ND & 0.24 & 1.13 & 2.10 & 3.83 \\
\hline $1,2,3,6,7,8-\mathrm{H} 6 \mathrm{CDF}$ & ND & ND & ND & ND & 0.12 \\
\hline $1,2,3,7,8,9-\mathrm{H} 6 \mathrm{CDF}$ & ND & ND & ND & ND & ND \\
\hline $2,3,4,6,7,8-\mathrm{H} 6 \mathrm{CDF}$ & ND & ND & ND & ND & ND \\
\hline $1,2,3,4,6,7,8-\mathrm{H} 7 \mathrm{CDF}$ & ND & 0.11 & 0.54 & 0.91 & 1.40 \\
\hline $1,2,3,4,7,8,9-\mathrm{H} 7 \mathrm{CDF}$ & ND & ND & ND & ND & ND \\
\hline OCDF & ND & 0.002 & 0.04 & 0.06 & 0.09 \\
\hline Total PCDD/F (pg-TEQ/g d.w.) & 0.42 & 333.98 & 1917.16 & 2913.65 & 3118.01 \\
\hline
\end{tabular}

the 4th week following to be decreased as ND in the 6 th week observation. To this data, the major accumulated dioxin in the oyster was the 2,3,7,8-T4CDD and 2,3,7,8-T4CDF, furthermore, the highest cumulative concentration was measured as 3746.16 (pgTEQ/g d.w.).

\subsection{Accumulation in white shrimp}

The concentration of PCDD/PCDF congener in white shrimps which were cultured with different concentration PCDD/PCDF sediment were under monitored. It was clear that the white shrimps which were cultured with high concentration PCDD/PCDF sediment exhibited higher accumulation and showed times and dose dependent. 2,3,7,8T4CDD was detected in all experimental groups; showed higher concentration then other PCDD/ PCDF congener and also was noted times and dose dependent. It was believed that white shrimp had a demersal habit. For that reason, the opportunity of white shrimp contact with sediment which contained dioxin was increased. Meanwhile, PCDD/F uptake rate was raised. Moreover, PCDD/F might be mingled with lipophilic feed, taken by white shrimp and piled up inside of white shrimp.

In the 2nd week, the 2,3,7, 8-Dioxin compounds were observed in the treatment groups but not in the control. In the 2,3,7,8-Furans compounds, 2,3,7,8-T4CDF and 1,2,3,7,8-P5CDF were observed in all of the groups (Table 12). In the 4th week, 2,3,7, 8Dioxins compounds were not detected in the control, however, these compounds were shown in the treatment groups. The OCDF was initial observed in the high treatment group (1500 ngTEQ/g d.w.) (Table 13). In the 6th week, 2,3,7,8-Dioxins were also observed in the treatment groups but not in the control, moreover, the OCDF was detected as ND, 0.003, 0.001, 0.001 and 0.002 (pgTEQ/g d.w.) in the control, 100, 500, 1000 and 1500 (ng-TEQ/g d.w.) (Table 14). In the 8th week, the detection trend was similar to the 6th week (Table 15).

Integration of this experiment, the OCDF was expression with the dioxin accumulated in the shrimp with the elapsed time, it was initially detected from the 6th week.

As these findings, the examination dioxin in the sediment was decreased with the elapsed time, however, detection of the dioxin in the water was maintain stability in the same treatment groups. Detection of the dioxin accumulated in the animal body, the accumulative maximum amounts was in the oyster as 3746.16 (pg-TEQ/g d.w.). The trend of accumulative dioxin in the oyster was undulated, however, it was increased with the elapsed time in the shrimp as Fig. 1.

\section{Discussion}

Pollution is a serious and complex chemical that affects organisms, the pollutants of the chemicals are a growing cause for concern respectively [15]. The high affinity of dioxins to the animal adipose 
Table 12. The accumulate dioxin concentration of the culture shrimp in the 2nd week. NOTE: ND means No detected and TEQ means Toxicity Equivalent.

\begin{tabular}{|c|c|c|c|c|c|}
\hline Dose (pg-TEQ/g d.w.) & $\mathrm{A}($ Control $)$ & B & $\mathrm{C}$ & $\mathrm{D}$ & $\mathrm{E}$ \\
\hline \multicolumn{6}{|l|}{ Native Compounds } \\
\hline 2,3,7,8-Dioxins & \multicolumn{5}{|c|}{ (pg-TEQ/g d.w.) } \\
\hline 2,3,7,8-T4CDD & ND & 28.99 & 176.80 & 243.65 & 272.28 \\
\hline 1,2,3,7,8-P5CDD & ND & 8.52 & 53.20 & 63.08 & 78.96 \\
\hline $1,2,3,4,7,8-\mathrm{H} 6 \mathrm{CDD}$ & ND & 0.71 & 3.85 & 4.83 & 6.31 \\
\hline 1,2,3,6,7,8-H6CDD & ND & 0.53 & 2.61 & 2.54 & 4.16 \\
\hline 1,2,3,7,8,9-H6CDD & ND & 0.51 & 2.69 & 2.99 & 4.58 \\
\hline $1,2,3,4,6,7,8-\mathrm{H} 7 \mathrm{CDD}$ & ND & 0.04 & 0.23 & 0.16 & 0.35 \\
\hline OCDD & ND & 0.01 & 0.01 & 0.01 & 0.02 \\
\hline 2,3,7,8-Furans & \multicolumn{5}{|c|}{ (pg-TEQ/g d.w.) } \\
\hline $2,3,7,8-\mathrm{T} 4 \mathrm{CDF}$ & ND & 2.66 & 13.98 & 21.64 & 24.27 \\
\hline $1,2,3,7,8-\mathrm{P} 5 \mathrm{CDF}$ & ND & 0.80 & 5.06 & 5.78 & 7.59 \\
\hline 2,3,4,7,8-P5CDF & ND & ND & ND & ND & ND \\
\hline $1,2,3,4,7,8-\mathrm{H} 6 \mathrm{CDF}$ & ND & 0.35 & 2.34 & 2.01 & 3.62 \\
\hline $1,2,3,6,7,8-\mathrm{H} 6 \mathrm{CDF}$ & ND & ND & ND & ND & ND \\
\hline 1,2,3,7,8,9-H6CDF & ND & ND & ND & ND & ND \\
\hline $2,3,4,6,7,8-\mathrm{H} 6 \mathrm{CDF}$ & ND & ND & ND & ND & ND \\
\hline $1,2,3,4,6,7,8-\mathrm{H} 7 \mathrm{CDF}$ & ND & 0.02 & 0.13 & 0.09 & 0.19 \\
\hline $1,2,3,4,7,8,9-\mathrm{H} 7 \mathrm{CDF}$ & ND & ND & ND & ND & ND \\
\hline OCDF & ND & ND & ND & 0.00 & ND \\
\hline Total PCDD/F (pg-TEQ/g d.w.) & ND & 43.13 & 260.91 & 346.78 & 402.33 \\
\hline
\end{tabular}

tissue and is capable to be accumulated. High dioxin dose is presented with the poisoning manifested as clinical symptoms by influence of the metabolic alteration [4]. The research was shown that the aryl hydrocarbon receptor (AHR) is a ligand-activated transcription factor that mediates dioxin-like compounds (DLCs) and some polycyclic aromatic hydrocarbons (PAHs). With strong AHR agonists, such as certain polychlorinated biphenyls and TCDD that may induce severe cardiac genesis in fish embryos [3]. Investigations have revealed that the source of egg contamination was the backyard soil on which the hens were foraging [20]. Moreover, agent orange $(\mathrm{AO})$ was the main defoliant used by

Table 13. The accumulate dioxin concentration of the culture shrimp in the 4th week. NOTE: ND means No detected and TEQ means Toxicity Equivalent.

\begin{tabular}{|c|c|c|c|c|c|}
\hline Dose (pg-TEQ/g d.w.) & $\mathrm{A}($ Control $)$ & B & $\mathrm{C}$ & $\mathrm{D}$ & E \\
\hline \multicolumn{6}{|l|}{ Native Compounds } \\
\hline 2,3,7,8-Dioxins & \multicolumn{5}{|c|}{ (pg-TEQ/g d.w.) } \\
\hline $2,3,7,8-\mathrm{T} 4 \mathrm{CDD}$ & ND & 38.56 & 238.68 & 365.48 & 362.13 \\
\hline $1,2,3,7,8-\mathrm{P} 5 \mathrm{CDD}$ & ND & 11.34 & 71.83 & 94.61 & 105.01 \\
\hline $1,2,3,4,7,8-\mathrm{H} 6 \mathrm{CDD}$ & ND & 0.94 & 5.20 & 7.24 & 8.39 \\
\hline $1,2,3,6,7,8-\mathrm{H} 6 \mathrm{CDD}$ & ND & 0.70 & 3.52 & 3.80 & 5.53 \\
\hline $1,2,3,7,8,9-\mathrm{H} 6 \mathrm{CDD}$ & ND & 0.68 & 3.63 & 4.49 & 6.09 \\
\hline $1,2,3,4,6,7,8-H 7 C D D$ & ND & 0.05 & 0.31 & 0.24 & 0.47 \\
\hline OCDD & ND & 0.02 & 0.02 & 0.01 & 0.02 \\
\hline 2,3,7,8-Furans & \multicolumn{5}{|c|}{ (pg-TEQ/g d.w.) } \\
\hline $2,3,7,8-\mathrm{T} 4 \mathrm{CDF}$ & ND & 3.53 & 18.46 & 28.57 & 32.04 \\
\hline $1,2,3,7,8-\mathrm{P} 5 \mathrm{CDF}$ & ND & 1.07 & 6.68 & 7.63 & 10.02 \\
\hline $2,3,4,7,8-\mathrm{P} 5 \mathrm{CDF}$ & ND & ND & ND & ND & ND \\
\hline $1,2,3,4,7,8-\mathrm{H} 6 \mathrm{CDF}$ & ND & 0.46 & 3.11 & 2.67 & 4.82 \\
\hline $1,2,3,6,7,8-\mathrm{H} 6 \mathrm{CDF}$ & ND & ND & ND & ND & ND \\
\hline $1,2,3,7,8,9-\mathrm{H} 6 \mathrm{CDF}$ & ND & ND & ND & ND & ND \\
\hline $2,3,4,6,7,8-\mathrm{H} 6 \mathrm{CDF}$ & ND & ND & ND & ND & ND \\
\hline $1,2,3,4,6,7,8-\mathrm{H} 7 \mathrm{CDF}$ & ND & 0.02 & 0.18 & 0.12 & 0.25 \\
\hline $1,2,3,4,7,8,9-\mathrm{H} 7 \mathrm{CDF}$ & ND & ND & ND & ND & ND \\
\hline OCDF & ND & ND & ND & ND & 0.00 \\
\hline Total PCDD/F (pg-TEQ/g d.w.) & ND & 57.37 & 351.61 & 514.87 & 534.78 \\
\hline
\end{tabular}


Table 14. The accumulate dioxin concentration of the culture shrimp in the 6th week. NOTE: ND means No detected and TEQ means Toxicity Equivalent.

\begin{tabular}{|c|c|c|c|c|c|}
\hline Dose (pg-TEQ/g d.w.) & $\mathrm{A}($ Control $)$ & B & $\mathrm{C}$ & $\mathrm{D}$ & $\mathrm{E}$ \\
\hline \multicolumn{6}{|l|}{ Native Compounds } \\
\hline 2,3,7,8-Dioxins & \multicolumn{5}{|c|}{ (pg-TEQ/g d.w.) } \\
\hline $2,3,7,8-\mathrm{T} 4 \mathrm{CDD}$ & ND & 46.27 & 286.42 & 438.58 & 434.56 \\
\hline 1,2,3,7,8-P5CDD & ND & 13.60 & 86.19 & 113.54 & 126.02 \\
\hline 1,2,3,4,7,8-H6CDD & ND & 1.13 & 6.23 & 8.69 & 10.07 \\
\hline $1,2,3,6,7,8-H 6 C D D$ & ND & 0.84 & 4.23 & 4.56 & 6.64 \\
\hline $1,2,3,7,8,9-\mathrm{H} 6 \mathrm{CDD}$ & ND & 0.81 & 4.35 & 5.38 & 7.30 \\
\hline $1,2,3,4,6,7,8-\mathrm{H} 7 \mathrm{CDD}$ & ND & 0.06 & 0.37 & 0.29 & 0.57 \\
\hline OCDD & ND & 0.02 & 0.02 & 0.01 & 0.03 \\
\hline 2,3,7,8-Furans & \multicolumn{5}{|c|}{ (pg-TEQ/g d.w.) } \\
\hline $2,3,7,8-\mathrm{T} 4 \mathrm{CDF}$ & ND & 3.89 & 20.31 & 31.43 & 35.24 \\
\hline $1,2,3,7,8-\mathrm{P} 5 \mathrm{CDF}$ & ND & 1.17 & 7.35 & 8.40 & 11.02 \\
\hline $2,3,4,7,8-\mathrm{P} 5 \mathrm{CDF}$ & ND & ND & ND & ND & ND \\
\hline $1,2,3,4,7,8-\mathrm{H} 6 \mathrm{CDF}$ & ND & 0.60 & 4.05 & 3.47 & 6.26 \\
\hline $1,2,3,6,7,8-\mathrm{H} 6 \mathrm{CDF}$ & ND & ND & ND & ND & ND \\
\hline $1,2,3,7,8,9-\mathrm{H} 6 \mathrm{CDF}$ & ND & ND & ND & ND & ND \\
\hline $2,3,4,6,7,8-\mathrm{H} 6 \mathrm{CDF}$ & ND & ND & ND & ND & ND \\
\hline $1,2,3,4,6,7,8-\mathrm{H} 7 \mathrm{CDF}$ & ND & 0.03 & 0.23 & 0.15 & 0.32 \\
\hline $1,2,3,4,7,8,9-\mathrm{H} 7 \mathrm{CDF}$ & ND & ND & ND & ND & ND \\
\hline OCDF & ND & 0.003 & 0.001 & 0.001 & 0.002 \\
\hline Total PCDD/F (pg-TEQ/g d.w.) & ND & 68.43 & 419.75 & 614.51 & 638.04 \\
\hline
\end{tabular}

the US in Vietnam from 1961 to 1971 and $\mathrm{AO}$ was contaminated with dioxin [19], which are known as carcinogenic chemicals [9].

Dioxin is a well-known strongly toxicity and persistent pollutant to reach aquatic environment through atmospheric deposition and contaminator sedimentation [16,27]. Dioxins are exposed mostly by the consumption of animal products and are able to enter the food chain at any stage, including crop fertilization [6]. Therefore, adverse effect of dioxin accumulation in seafood should be concern [1,2]. Department of Health (Taiwan) have defined a limited value of dioxin in marine food product $(<4$ pg-TEQ/g) and Environmental Protection

Table 15. The accumulate dioxin concentration of the culture shrimp in the 8th week. NOTE: ND means No detected and TEQ means Toxicity Equivalent.

\begin{tabular}{|c|c|c|c|c|c|}
\hline Dose (pg-TEQ/g d.w.) & $\mathrm{A}($ Control $)$ & B & $\mathrm{C}$ & $\mathrm{D}$ & $\mathrm{E}$ \\
\hline \multicolumn{6}{|l|}{ Native Compounds } \\
\hline 2,3,7,8-Dioxins & \multicolumn{5}{|c|}{ (pg-TEQ/g d.w.) } \\
\hline $2,3,7,8-\mathrm{T} 4 \mathrm{CDD}$ & ND & 41.23 & 232.00 & 530.68 & 516.30 \\
\hline 1,2,3,7,8-P5CDD & ND & 11.02 & 69.81 & 91.96 & 102.07 \\
\hline $1,2,3,4,7,8-\mathrm{H} 6 \mathrm{CDD}$ & ND & 0.91 & 5.05 & 7.04 & 8.16 \\
\hline $1,2,3,6,7,8-\mathrm{H} 6 \mathrm{CDD}$ & ND & 0.68 & 3.42 & 3.70 & 5.38 \\
\hline $1,2,3,7,8,9-\mathrm{H} 6 \mathrm{CDD}$ & ND & 0.66 & 3.52 & 4.36 & 5.92 \\
\hline $1,2,3,4,6,7,8-H 7 C D D$ & ND & 0.05 & 0.30 & 0.24 & 0.46 \\
\hline OCDD & ND & 0.02 & 0.02 & 0.01 & 0.02 \\
\hline 2,3,7,8-Furans & \multicolumn{5}{|c|}{ (pg-TEQ/g d.w.) } \\
\hline $2,3,7,8-\mathrm{T} 4 \mathrm{CDF}$ & ND & 3.50 & 24.37 & 27.97 & 50.29 \\
\hline $1,2,3,7,8-\mathrm{P} 5 \mathrm{CDF}$ & ND & 1.05 & 6.54 & 6.63 & 10.91 \\
\hline 2,3,4,7,8-P5CDF & ND & ND & ND & ND & ND \\
\hline $1,2,3,4,7,8-\mathrm{H} 6 \mathrm{CDF}$ & ND & 0.54 & 3.64 & 3.13 & 5.64 \\
\hline $1,2,3,6,7,8-\mathrm{H} 6 \mathrm{CDF}$ & ND & ND & ND & ND & ND \\
\hline $1,2,3,7,8,9-\mathrm{H} 6 \mathrm{CDF}$ & ND & ND & ND & ND & ND \\
\hline $2,3,4,6,7,8-\mathrm{H} 6 \mathrm{CDF}$ & ND & ND & ND & ND & ND \\
\hline $1,2,3,4,6,7,8-\mathrm{H} 7 \mathrm{CDF}$ & ND & 0.03 & 0.21 & 0.14 & 0.29 \\
\hline $1,2,3,4,7,8,9-\mathrm{H} 7 \mathrm{CDF}$ & ND & ND & ND & ND & ND \\
\hline OCDF & ND & 0.002 & 0.001 & 0.001 & 0.002 \\
\hline Total PCDD/F (pg-TEQ/g d.w.) & ND & 59.69 & 348.89 & 675.85 & 705.44 \\
\hline
\end{tabular}


Administration (Taiwan) have also defined a restriction of dioxin in sediment $(<1000 \mathrm{ng}-\mathrm{TEQ} / \mathrm{kg})$. However, the results of this study showed that the dioxin residues in oyster and white shrimp cultured in a tank which contained with PCDD/F (1000 pgTEQ/g) had higher value than $4 \mathrm{pg}-\mathrm{TEQ} / \mathrm{g}$. As the result, oyster and white shrimp which were cultured with sediment contained 1500 ng-TEQ/g showed that the lower residue value was 3746.16 and 705.44 (pg-TEQ/g) respectively. Even in other experimental group, the residues of dioxin in oyster or white shrimp also showed higher value than the restriction. According to the result, the residues of dioxin in marine animal would magnify while the dioxin concentration in sediment increased as a result of bioaccumulation and bio-magnifications in the aquatic food chain. Furthermore, the dioxin absorb efficiency is not the same in different aquatic animals similar to our findings [24].

In previous, it is evidenced of water quality directly affects aquatic organisms. Research had evidenced that the sediment and soil played as conservative matrices to record PCDD/F input. In addition, $\mathrm{PCDD} / \mathrm{Fs}$ have entered the catchment area via different route of environmental transports to impact the sediment [5]. Moreover, dioxins are transported in aquatic environments while sodium pentachlorophenate used in the 1960s and the 1980s [11] and accumulated to the toxic effects. Analysis of chemicals accumulation in muscle of tilapia are mainly originated from sediment [14]. In this research, the level of dioxin is significant detected in the oyster than in the white shrimp. Based on this finding, it was supposed that the dioxin accumulation in the filter habit animals is greater than the demersal animals. Integration of these findings, suggestion that the adaptable dioxin concentration in sediment is supposed to be serious consideration in aquaculture.

Our results presented that the dissolution of pond water, will increase sediment dioxin content rises, but dioxin is fat-soluble substances, the dissolution of dioxin amount is entrained with the suspended material. Each treatment was found that the samples were detected with the highest toxic dioxin isomer content of 2,3,7,8-T4CDD equivalency factors and the configuration concentration of the sediment dioxin residues was slightly decreased but the organism was increased with the time. Suspected that the pre-existing sediment dioxin gradually accumulated in the cultured organism. The oyster was purchased from the fish market and analysis of the dioxin concentration before initiation of the research and it was exactly observed. Based on that, the dioxin accumulation in the oyster was higher than the total concentration in the culture system.

Dioxins in the food chain is mainly by the organism. Therefore, in the ecosystems bio-concentration, the dioxin is fat-soluble substance and in the sediment or suspended matter. The experiment shrimp was benthic organisms contacted with the sediment frequently with dioxin resulting to the dioxin residue in the body.

Oyster was filter-feeding organisms, which feed water for the green algae or plankton in water or suspended matter, dioxin may also be present in suspension in the water organisms as water green algae, plankton and other organisms in the water or in the organism, resulting in the accumulation of residual in the oyster body.

\section{Conclusion}

1. 2,3,7,8-T4CDD was the major accumulation compound in the oyster and white shrimp.

2. With the elapsed time, the oyster dioxin accumulation was fast increased to the maximum observation concentration of $3746.16(\mathrm{pg}-\mathrm{TEQ} / \mathrm{g})$ than the white shrimp.

3. In the white shrimp, the OCDF was accumulated in the body with the time after 4 week's observation.

4. In the water, the dioxin accumulation concentration is lower than in the animal. By these findings, the filter habit animal "oyster" was higher accumulated with dioxin than the benthic animal "white shrimp".

\section{Declaration of competing interest}

None of the authors has a financial relationship with a commercial entity that has an interest in the subject of this manuscript.

\section{References}

[1] Becher H, Flesch-Janys D. Dioxins and furans: epidemiologic assessment of cancer risks and other human health effects. Environ Health Perspect 1998;106:623-4.

[2] Bergkvist C, Oberg M, Appelgren M, Becker W, Aune M, Ankarberg EH, et al. Exposure to dioxin-like pollutants via different food commodities in Swedish children and young adults. Food Chem Toxicol 2008;46:3360-7.

[3] Brown DR, Clark BW, Garner LV, Giulio RTD. Zebrafish cardiotoxicity: the effects of CYP1A inhibition and AHR2 knockdown following exposure to weak aryl hydrocarbon receptor agonists. Environ Sci Pollut Res 2015;22: 8329-38.

[4] Calkosinski I, Rosinczuk-Tonderys J, Bazan J, Dobrzynski M, Bronowicka-Szydelko A, Dzierzba K. Influence of dioxin intoxication on the human system and possibilities of 
limiting its negative effects on the environment and living organisms. Ann Agric Environ Med 2014;21:518-24.

[5] Chang HJ, Wang S, Li SW, Lin KH, Chao CC, Lai YC. Polychlorinated dibenzo-p-dioxins and dibenzofuran contents in fish and sediment near a pentachlorophenol contaminated site. J Environ Sci Health Part A 2010;45:923-31.

[6] Charnley G, Doull J. Human exposure to dioxins from food, 1999-2002. Food Chem Toxicol 2005;43:671-9.

[7] Chen HL, Lee CC, Liao PC, Guo YL, Chen CH, Su HJ. Associations between dietary intake and serum polychlorinated dibenzo-p-dioxin and dibenzofuran (PCDD/F) levels in Taiwanese. Environ Res 2003;91:172-8.

[8] Consonni D, Sindaco R, Bertazzi PA. Blood levels of dioxins, furans, dioxin-like PCBs, and TEQs in general populations: a review, 1989-2010. Environ Int 2012;44:151-62.

[9] Dang TH, Igarashi T, Shiraiwa T. Utilization of soil properties to understand the vertical distribution of dioxins in the soil of Bien Hoa airbase, Vietnam. Environ Earth Sci 2016;75: 1-8.

[10] Dyke P, Foan C, Wenborn M, Coleman P. A review of dioxin releases to land and water in the UK. Sci Total Environ 1997; 207:119-31.

[11] Gao L, Zhang Q, Zhang B, Liu W, Xiao K. Polychlorinated dibenzo-p-dioxins and dibenzofurans in water and six fish species from Dongting Lake, China. Chemosphere 2014;114: $150-7$.

[12] Hayward DG. Determination of polychlorinated dibenzo-pdioxin and dibenzofuran background in milk and cheese by quadrupole ion storage collision induced dissociation MS/ MS. Chemosphere 1997;34:929-39.

[13] Leijs MM, Tusscher GW, Olie K, van Teunenbroek T, van Aalderen WM, de Voogt $\mathrm{P}$, et al. Thyroid hormone metabolism and environmental chemical exposure. Environ Health 2012;11:1-10.

[14] Ling MP, Wu CC, Yang KR, Hsu HT. Differential accumulation of trace elements in ventral and dorsal muscle tissues in tilapia and milkfish with different feeding habits from the same cultured fishery pond89; 2013. p. 222-30.

[15] Liu J, Lewis G. Environmental toxicity and poor cognitive outcomes in children and adults. J Environ Health 2014;76: $130-8$.
[16] Lohmann R, Jones KC. Dioxins and furans in air and deposition: a review of levels, behaviour and processes. Sci Total Environ 1998;219:53-81.

[17] Manikkam M, Tracey R, Guerrero-Bosagna C, Skinner MK. Dioxin (TCDD) induces epigenetic transgenerational inheritance of adult onset disease and sperm epimutations. PloS One 2012;7:e46249.

[18] Parzefall W. Risk assessment of dioxin contamination in human food. Food Chem Toxicol 2002;40:1185-9.

[19] Pham DT, Nguyen HM, Boivin TG, Zajacova A, Huzurbazar SV, Bergman HL. Predictors for dioxin accumulation in residents living in da Nang and bien Hoa, Vietnam, many years after agent orange use. Chemosphere 2015;118:277-83.

[20] Piskorska-Pliszczynska J, Mikolajczyk S, Warenik-Bany M, Maszewski S, Strucinski P. Soil as a source of dioxin contamination in eggs from free-range hens on a polish farm. Sci Total Environ 2014;466:447-54.

[21] Pohl H, DeRosa C, Holler J. Public health assessment for dioxins exposure from soil. Chemosphere 1995;31:2437-54.

[22] Rappe C, Bergqvist PA, Kjeller LO, Swanson S, Belton T, Ruppel B, et al. Levels and patterns of PCDD and PCDF contamination in fish, crabs, and lobsters from Newark Bay and the New York Bight. Chemosphere 1991;22:239-66.

[23] Ruus A, Berge JA, Bergstad OA, Knutsen JA, Hylland K Disposition of polychlorinated dibenzo-p-dioxins (PCDDs) and polychlorinated dibenzofurans (PCDFs) in two Norwegian epibenthic marine food webs. Chemosphere 2006;62:1856-68.

[24] Sakurai T, Kim JG, Suzuki N, Matsuo T, Li DQ, Yao Y, et al. Polychlorinated dibenzo-p-dioxins and dibenzofurans in sediment, soil, fish, shellfish and crab samples from Tokyo Bay area, Japan. Chemosphere 2000;40:627-40.

[25] Schecter A. Dioxins and health. Springer Science \& Business Media; 2013. p. 55-63.

[26] Soave I, Caserta D, Wenger J, Dessole S, Perino A, Marci R. Environment and Endometriosis: a toxic relationship. Eur Rev Med Pharmacol Sci 2015;19:1964-72.

[27] Tung JWT, Yu JZ, Lau AKH, Louie PK. Abundance and sources of ambient dioxins in Hong Kong: a review of dioxin measurements from 1997 to 2001. Chemosphere 2005;59: 1387-98. 